\title{
COMPONENTES NÃO CARCAÇA DE NOVILHOS DE CORTE SUBMETIDOS À CASTRAÇÃO CIRÚRGICA OU IMUNOLÓGICA
}

\author{
NON CARCASS COMPONENTS STEERS SUBMITTED SURGICALLY \\ CASTRATION OR IMMUNOLOGICAL CASTRATION
}

\author{
Diego Soares Machado ${ }^{*}$ \\ Dari Celestino Alves Filho ${ }^{1}$ \\ Ivan Luiz Brondani ${ }^{1}$ \\ Flânia Mônego Argenta ${ }^{1}$ \\ Lucas Braido Pereira ${ }^{2}$ \\ Marcelo Ascoli da Silva ${ }^{1}$ \\ 1 Universidade Federal de Santa Maria, Santa Maria, RS, Brasil. \\ ${ }^{2}$ Instituto Federal Farroupilha, Alegrete, RS, Brasil. \\ *Autor para correspondência - dsoaresmachado@ymail.com
}

\section{Resumo}

Objetivou-se avaliar as características dos componentes do corpo vazio que não integram a carcaça de novilhos castrados cirurgicamente ou imunologicamente. Foram utilizados 48 bezerros Aberdeen Angus, monitorados a partir de idade média inicial de seis meses e peso médio inicial de $160 \mathrm{~kg}$. Os animais foram distribuídos nos seguintes tratamentos: castrados cirurgicamente ao nascimento; castrados cirurgicamente à desmama; imunocastrados com três doses de vacina $\left(6^{\circ}, 9^{\circ}\right.$ e $14^{\circ}$ meses de idade dos animais) e imunocastrados com quatro doses $\left(6^{\circ}, 7^{\circ}, 10^{\circ} \mathrm{e} 15^{\circ}\right.$ meses de idade dos animais). $\mathrm{O}$ delineamento experimental foi o inteiramente casualizado. Durante o abate, todos os componentes internos e externos do corpo do animal foram separados e pesados individualmente. $\mathrm{O}$ total de órgãos internos expressos em percentual do peso de corpo vazio diferiu entre os dois protocolos de imunocastração, com superioridade quando aplicou-se quatro doses $(3,61$ vs. 3,39 kg). Novilhos castrados ao nascer depositaram mais gordura cardíaca, renal e pélvica, e gordura do trato gastrintestinal que imunocastrados com três doses, independentemente da forma como foi expressa. A castração cirúrgica ao nascimento promove maior deposição de gordura visceral, em novilhos abatidos em idade jovem, em relação à imunocastração com dosagem definitiva com nove meses de idade.

Palavras-chave: bem-estar animal; gordura visceral; órgãos vitais; peso de corpo vazio.

\begin{abstract}
The objective was to evaluate the characteristics of empty body components that are not part of the carcass of steers surgically or immunologically castrated. Forty-eight Aberdeen Angus calves were used and monitored since six months of age and $160 \mathrm{~kg}$ of average weight. The animals were divided into the following treatments: surgically castrated at birth; Surgically castrated at weaning; Immunocastrated with three doses immunocastrated of vaccine $\left(6^{\text {th }}, 9^{\text {th }}\right.$ and $14^{\text {th }}$ months of age of the animals) and immunocastrated with four doses $\left(6^{\text {th }}, 7^{\text {th }}, 10^{\text {th }}\right.$ and $15^{\text {th }}$ months of age of the animals). The experimental design used was the completely randomized. During the slaughter, all internal and
\end{abstract}


external components of animal body were separated and weighed individually. The total internal organs, expressed in percentage of empty body weight, differed between the two protocols of immunocastration, with superiority when it was applied four doses (3.61 vs. $3.39 \mathrm{~kg})$. Steers castrated at birth deposited more cardiac, kidney and pelvic fat, and fat of the gastrointestinal tract that immunocastrated with three doses, regardless of how it was expressed. Surgical castration at birth promotes greater deposition of visceral fat at the slaughtered in young steers in relation to immunocastration with definitive dosage at nine months of age.

Keywords: animal welfare; empty body weight; visceral fat; vital organs.

Recebido em: 20 de julho de 2017

Aceito em: 27 de outubro de 2017

\section{Introdução}

O elevado número de bovinos abatidos no Brasil, visando atender à crescente demanda mundial por proteína vermelha gera não só o produto carne, mas também outros tantos componentes, necessitando cada vez mais a destinação correta dos mesmos. Com isso, nos últimos anos tem-se enfatizado o estudo dos componentes não carcaça como consequência da valorização dos órgãos aptos ao consumo, do couro e dos resíduos usados pela indústria de rações e, principalmente, por esses componentes estarem associados ao rendimento de carcaça ${ }^{(1)}$. Para a indústria frigorífica, um bom aproveitamento dos componentes não carcaça reflete em melhor remuneração pelos animais $\operatorname{abatidos}^{(2)}$.

$\mathrm{Na}$ atualidade existe um grande foco de estudo na forma como o animal está sendo criado que abrange as áreas de bem-estar dos funcionários e dos animais, meio ambiente, responsabilidade social, segurança alimentar, saúde humana, entre outros ${ }^{(3)}$. Diante desta conjectura, o estudo da condição sexual, que pode ser manipulada através da metodologia de castração, abrange praticamente a totalidade dos fatores citados acima. Muitas vezes, a tomada de decisão de castrar ou não bovinos machos depende de estratégias de mercado, em que a indústria pode ou não remunerar por uma carne de maior qualidade. Tradicionalmente, o método de castração predominantemente utilizado no Brasil é o método cirúrgico, porém na maioria das vezes este é realizado de maneira inadequada, tornandose uma técnica questionável do ponto de vista do bem-estar animal. Diante deste prisma, desenvolveuse recentemente a castração imunológica contra $\mathrm{GnRH}$, caracterizando-se por ser uma tecnologia menos invasiva e por consequência menos traumática.

Por ser uma tecnologia relativamente recente, existem poucos estudos do seu reflexo nas características de carcaça e carne, em que os autores constataram poucas diferenças em relação à castração cirúrgica $^{(4,5)}$. No entanto, quando buscamos informações do efeito sobre as partes não integrantes da carcaça os resultados são escassos ou inexistentes. Portanto, faz-se necessário estudar os efeitos da imunocastração sobre os componentes não integrantes da carcaça, frente à castração cirúrgica. Dessa forma, o objetivo do presente trabalho foi avaliar os componentes não carcaça de novilhos castrados cirurgicamente em duas idades ou imunologicamente em dois protocolos. 


\section{Material e Métodos}

Este trabalho foi analisado e aprovado pela Comissão de Ética no Uso de Animais da Universidade Federal de Santa Maria, protocolado sob o $\mathrm{n}^{\mathrm{o}}$. 6976300415. O estudo foi realizado na fazenda Paineiras, situada no município de São Vicente do Sul - RS. Foram utilizados 48 bezerros da raça Aberdeen Angus, monitorados a partir do nascimento, permanecendo ao pé da vaca até o desmame. $\mathrm{O}$ nascimento dos bezerros ocorreu entre os meses de setembro e novembro. À medida que foram ocorrendo os nascimentos, os animais foram sendo distribuídos nos grupos estudados para uma uniformização na média de idade dos bezerros, em todos os tratamentos. Na ocasião do desmame os bezerros apresentavam idade média de seis meses e peso médio de $160 \mathrm{~kg}$. Os animais foram distribuídos aleatoriamente em quatro tratamentos com 12 repetições em cada, sendo: castração cirúrgica ao nascer; castração cirúrgica à desmama; castração imunológica com três doses da vacina Bopriva $^{\circledR}$, no $6^{\circ}, 9^{\circ}$, e $14^{\circ}$ meses de idade dos animais; castração imunológica com quatro doses da vacina Bopriva ${ }^{\circledR}$, no $6^{\circ}, 7^{\circ}, 10^{\circ}$ e $15^{\circ}$ meses de idade dos animais. A partir do início das imunizações, os animais que receberam três doses da vacina foram imunizados nos dias 1, 90 e 242, enquanto os que receberam quatro doses foram imunizados nos dias 1, 30, 120 e 270. A castração cirúrgica à desmama ocorreu na mesma data da vacinação do dia 1.

De acordo com o fabricante da vacina, para o animal ser considerado imunocastrado, faz-se necessário duas aplicações (dose + reforço) com supressão da testosterona entre sete e 14 dias após o reforço e período de ação variando conforme o intervalo entre dosagens. Quando desejado podem ser realizadas aplicações subsequentes. A vacina Bopriva ${ }^{\circledR}$, para imunocastração de bovinos, é constituída de um análogo de GnRF ligado a uma proteína carreadora. É adicionado à vacina um adjuvante sintético aquoso que aumenta o nível e duração da imunidade. Cada $\mathrm{mL}$ da vacina fornece $400 \mu \mathrm{g}$ do conjugado de GnRF e proteína carreadora. Este produto é injetável e estimula o sistema imune a produzir anticorpos contra $\mathrm{GnRH}$, hormônio precursor dos hormônios sexuais, castrando assim o animal. O produto ainda tem como características não ser considerado castrador químico, não é hormônio e não exige período de carência para o abate.

Todas as vacinações com a vacina foram realizadas do lado esquerdo do pescoço, por via subcutânea, na dosagem de $1 \mathrm{~mL}$ por animal. Tanto as aplicações da vacina como os procedimentos cirúrgicos foram realizados por médico veterinário. A contenção dos bezerros castrados ao nascimento foi realizada manualmente, enquanto que para os castrados ao desmame essa foi realizada em tronco de contenção. Em ambos os grupos, após a constatação dos testículos na bolsa escrotal, aplicou-se anestesia local com lidocaína a $2 \%$ na dosagem de $6 \mathrm{mg} / \mathrm{Kg}$ de peso corporal, em cada cordão espermático. Após esse procedimento, foi realizada a incisão da pele e expostos os testículos para secção destes com auxílio de bisturi (lâmina $n^{\circ}$. 24) esterilizado e posteriormente foi realizada ligadura dos cordões espermáticos com fio de sutura absorvível (Poliglactina 910). Foram aplicados também uma pomada cicatrizante e repelente no local da incisão e por via subcutânea um endectocida injetável de amplo espectro à base de doramectina a $1 \%$ na dosagem de $0,2 \mathrm{mg} / \mathrm{kg}$ peso corporal. Os procedimentos cirúrgicos seguiram a resolução $N^{\circ}$ 928, do Conselho Federal de Medicina Veterinária $^{(6)}$.

Todos os animais permaneceram sempre juntos submetidos às mesmas condições nutricionais, sanitárias e ambientais, desde o nascimento até o abate. Durante a fase de aleitamento, os animais permaneceram ao pé da mãe, onde o conjunto vaca/bezerro permaneceu em pastagem natural, 
recebendo suplementação mineral à vontade. Após o desmame, realizado em 17 de abril, iniciou-se a fase de recria dos animais, que foram mantidos exclusivamente em pastagem de aveia preta (Avena strigosa Shreb) + azevém (Lolium multiflorum Lam.), até 23 de outubro.

Durante a terminação, compreendida de 23 de outubro a 22 de maio, os animais foram mantidos em duas áreas de pastagem natural, em sistema de pastejo rotacionado. A cada 30 dias ocorreu o rodízio de piquetes, ficando uma das áreas sempre em pousio. Na fase de terminação os novilhos foram suplementados com ração comercial, na ordem de $1 \%$ do peso corporal, com base na matéria seca (MS). A ração comercial utilizada continha 767,3 g MS/kg de matéria natural; 168,0 g de proteína bruta/kg MS; 107,6 g extrato etéreo/kg MS; 176,8 g fibra detergente neutro/kg MS; 158,7 g fibra detergente ácido/kg MS e 767,3 g nutrientes digestíveis totais/kg MS. A suplementação mineral foi realizada conforme manejo da fazenda em comedouros cobertos e o acesso à água foi em bebedouros e lagoas.

O abate foi pré-determinado para quando os animais atingissem peso de carcaça quente estimado de $200 \mathrm{~kg}$, com rendimento de carcaça ao redor de 53\%. Após jejum de sólidos e líquidos de 12 horas, antes de serem embarcados para o frigorífico, os animais foram pesados individualmente (peso de abate). Os animais foram abatidos em frigorífico comercial com inspeção estadual. O transporte dos animais até o frigorífico teve tempo decorrido de duas horas, em uma distância de $90 \mathrm{~km}$. Os pesos de abate foram: 379,5; 353,8; 382,9 e 372,5, respectivamente, para os novilhos castrados cirurgicamente ao nascimento, castrados cirurgicamente ao desmame, imunocastrados com três doses e imunocastrados com quatro doses.

Durante o abate, todas as partes do corpo do animal foram separadas e pesadas individualmente, e consistiram de: conjunto de componentes externos - cabeça, aparas (somatório de patas, orelhas e vassoura da cauda) e couro; conjunto de órgãos vitais - pulmão, fígado, rins, coração e baço; conjunto do trato gastrintestinal vazio: rúmen-retículo, omaso, abomaso, intestinos (grosso + delgado); conjunto de gorduras do trato gastrintestinal; conjunto de gorduras cardíaca, pélvica e renal; gordura de toalete; e sangue. Antes de serem encaminhadas à câmara de resfriamento, as duas meias-carcaças foram identificadas e pesadas, obtendo-se o peso de carcaça quente. Pelo somatório do peso de carcaça quente, sangue e de todos os componentes agrupados conforme citado anteriormente foi obtido o peso de corpo vazio (PCV).

Após o período de resfriamento das carcaças por 24 horas em temperatura oscilando entre zero e $1^{\circ} \mathrm{C}$, estas foram novamente pesadas para obtenção do peso de carcaça fria. Com estas duas pesagens (carcaça quente e fria), determinaram-se os rendimentos de carcaça quente e fria, respectivamente, referentes ao peso de corpo vazio. Ainda por ocasião do abate, os animais imunocastrados tiveram os testículos retirados da bolsa escrotal, pesados em balança digital e medidos individualmente, quanto ao comprimento e perímetro.

O delineamento experimental utilizado foi o inteiramente casualizado, com quatro tratamentos e 12 repetições. Os dados coletados foram testados quanto à normalidade pelo teste de Shapiro-Wilk, sendo realizadas transformações quando necessário. Posteriormente, foram submetidos à análise de variância pelo teste $\mathrm{F}$, através do PROC GLM. As variáveis dependentes foram submetidas à análise de Correlação de Pearson através do PROC CORR. As análises estatísticas foram realizadas através do pacote estatístico $S A S^{\circledR}$ Studio University Edition, versão 3.5. As médias foram comparadas com o teste de Tukey em nível de 5\% de probabilidade. O modelo matemático empregado na análise de variância foi:

$$
\gamma_{\mathrm{jk}}=\mu+\tau_{\mathrm{j}}+\varepsilon_{\mathrm{jk}}
$$


Em que: $\gamma_{\mathrm{jk}}=$ variáveis dependentes; $\mu=$ média de todas as observações; $\tau_{\mathrm{j}}=$ efeito do $\mathrm{j}$-ésimo tratamento; $\varepsilon_{\mathrm{jk}}=$ efeito aleatório associado à observação $\gamma_{\mathrm{jk}}$, pressuposto NID $\left(0 ; \sigma^{2}\right)$.

\section{Resultados e Discussões}

O peso de corpo vazio (PCV) não foi influenciado pelos tratamentos avaliados (Tabela 1). Embora as castrações tenham ocorrido em diferentes idades do animal, e dessa forma com possibilidade de um pequeno aporte do hormônio testosterona, principalmente do grupo imunocastrado com ação definitiva aos nove meses, este fato não foi suficiente para promover diferenças substanciais no peso de abate e consequentemente no PCV.

Tabela 1. Médias, coeficiente de variação e probabilidade para peso de corpo vazio, relação peso de corpo vazio/peso de abate (PCV/PAB) e os rendimentos de carcaça quente (RCQ) e fria (RCF) em relação ao peso de corpo vazio

\begin{tabular}{|c|c|c|c|c|c|c|}
\hline \multirow{3}{*}{ Variáveis } & \multicolumn{4}{|c|}{ Castração } & \multirow{3}{*}{$\begin{array}{l}\text { CV } \\
(\%)\end{array}$} & \multirow{3}{*}{ P valor } \\
\hline & \multicolumn{2}{|c|}{ Cirúrgica } & \multicolumn{2}{|c|}{ Imunológica } & & \\
\hline & Nascer & Desmame & 3 doses & 4 doses & & \\
\hline Peso de corpo vazio, $\mathrm{kg}$ & 313,9 & 292,0 & 310,4 & 309,9 & 8,96 & 0,2162 \\
\hline $\mathrm{PCV} / \mathrm{PAB}, \%$ & 82,64 & 82,63 & 81,12 & 83,28 & 2,57 & 0,0957 \\
\hline $\mathrm{RCQ}, \% \mathrm{PCV}$ & 65,66 & 65,25 & 65,67 & 64,85 & 1,73 & 0,2490 \\
\hline $\mathrm{RCF}, \% \mathrm{PCV}$ & 64,30 & 63,58 & 64,11 & 63,40 & 1,71 & 0,1530 \\
\hline
\end{tabular}

Cabe salientar ainda que todas as castrações ocorreram com os animais ainda em idade pré-púbere, o que também contribui para não haver modificações significativas no desenvolvimento dos mesmos desencadeando em peso de corpo vazio semelhante. O resultado obtido para o peso de corpo vazio está intimamente ligado ao peso de abate, havendo correlação alta e positiva entre estes pesos ( $\mathrm{r}=0,96$; $\mathrm{P}<0,0001$ ). Estes resultados corroboram com Cattelam et al. ${ }^{(7)}$, que encontraram correlação de 0,98 entre peso de corpo vazio e peso de abate em novilhos cruzados Charolês x Nelore terminados em confinamento.

Observa-se que as respostas das demais variáveis encontradas na Tabela 1 apresentam comportamento semelhante ao verificado para PCV, onde a similaridade dos resultados corrobora com a teoria elaborada acima. Apesar da não observância de diferenças nos resultados, cabe discutir a magnitude dos mesmos, em que a relação PCV/PAB, que representa o rendimento de corpo vazio, ficou abaixo dos valores encontrados por Kuss et al. ${ }^{(1)}$, que obtiveram valores de 91,31 e 90,38\%, respectivamente, para novilhos castrados e não castrados, porém sem influência do gênero sobre o rendimento de corpo vazio. Todavia, no presente estudo a terminação dos novilhos ocorreu em pastagem natural, com suplementação, diferentemente do estudo acima citado, em que eram novilhos confinados.

O menor rendimento obtido neste estudo está relacionado ao tipo de alimentação em que a pastagem natural, principalmente na época de condução da pesquisa apresenta baixa digestibilidade, reduzindo a taxa de passagem da digesta, o que acarreta aumento do conteúdo do trato gastrintestinal e, por 
consequência, reduz o rendimento de corpo vazio. A comparação da relação PCV/PAB entre diferentes estudos deve imprescindivelmente levar em consideração diferenças no tempo de jejum e o tipo de $\operatorname{dieta}^{(8)}$.

Os rendimentos de carcaça quente (RCQ) e fria (RCF), expressos em relação ao peso de corpo vazio, não foram influenciados pelas estratégias de castração $(\mathrm{P}>0,05)$, com valores médios, respectivamente de 65,36 e 63,85\% (Tabela 1). Os rendimentos de carcaça, relativos ao peso corporal vazio são dependentes da participação dos componentes não carcaça, logo neste estudo as variações encontradas em algumas partes do corpo dos novilhos que não compõem a carcaça não foram suficientes para alterar seus rendimentos. Foram obtidos coeficientes de correlação negativos entre os rendimentos de carcaça e os componentes não carcaça, ambos ajustados ao peso corporal vazio. $\mathrm{O}$ RCQ correlacionou-se negativamente com o somatório de órgãos externos $(\mathrm{r}=-0,49 ; \mathrm{P}=0,0004)$, somatório de órgãos internos $(\mathrm{r}=-0,38 ; \mathrm{P}=0,0070)$, trato gastrintestinal $(\mathrm{r}=-0,47 ; \mathrm{P}=0,0007)$ e somatório de gorduras viscerais e de toalete $(\mathrm{r}=-0,31 ; \mathrm{P}=0,0293)$. Já o $\mathrm{RCF}$ apresentou valores de correlação de $-0,50(\mathrm{P}=0,0002) ;-0,36(\mathrm{P}=0,0101) ;-0,46(\mathrm{P}=0,0010)$, com os componentes citados acima na mesma ordem, exceto o somatório de gorduras, que não apresentou correlação significativa com RCF.

Os valores de rendimento encontrados neste estudo são similares aos verificados por Cattelam et al. ${ }^{(7)}$, que estudaram novilhos castrados e não castrados, e obtiveram rendimentos médios de carcaça quente e carcaça fria, em relação ao peso corporal vazio, similares entre as condições sexuais.

Os componentes periféricos, expressos em peso absoluto e, em relação ao peso de corpo vazio foram similares entre os métodos e idades de castração (Tabela 2). Por serem animais de mesma raça e submetidos às mesmas condições de meio, variando apenas a estratégia de castração, já se esperava similaridade nos componentes periféricos, a partir do momento em que se constatou que os pesos de abate e de corpo vazio dos novilhos também foram similares.

Tabela 2. Médias, coeficiente de variação e probabilidade dos componentes externos da carcaça expressos em peso absoluto $(\mathrm{kg})$ e por $100 \mathrm{~kg}$ de corpo vazio (PCV) de novilhos submetidos à castração cirúrgica ou imunológica

\begin{tabular}{lccccccc}
\hline \multirow{2}{*}{ Variáveis } & \multicolumn{5}{c}{ Castração } & CV & \multirow{2}{*}{ P valor } \\
\cline { 2 - 5 } & \multicolumn{2}{c}{ Cirúrgica } & \multicolumn{2}{c}{ Imunológica } & & (\%) & \\
\cline { 2 - 5 } & Nascer & Desmame & 3 doses & 4 doses & & \\
\hline${ }^{1}$ Aparas, kg & 8,32 & 8,17 & 8,37 & 8,24 & 10,45 & 0,9384 \\
1'Aparas, \% PCV & 2,66 & 2,79 & 2,70 & 2,66 & 6,29 & 0,1856 \\
Cabeça, kg & 12,73 & 12,05 & 12,88 & 12,62 & 6,84 & 0,1078 \\
Cabeça, \% PCV & 4,06 & 4,13 & 4,15 & 4,09 & 5,21 & 0,7483 \\
Couro, kg & 28,62 & 27,75 & 30,95 & 30,85 & 14,74 & 0,1952 \\
Couro, \% PCV & 9,12 & 9,49 & 9,96 & 9,92 & 9,94 & 0,1223 \\
Total de externos, kg & 49,67 & 47,97 & 52,22 & 51,71 & 10,92 & 0,2247 \\
Total externos, \% PCV & 15,85 & 16,42 & 16,82 & 16,67 & 5,85 & 0,0851 \\
\hline
\end{tabular}

Médias seguidas na linha com letras diferentes diferem entre si pelo teste de Tukey $(\mathrm{P}<0,05)$.

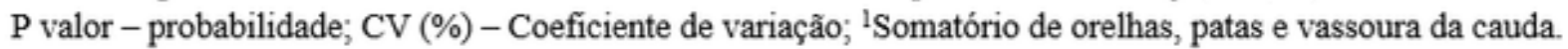


Os coeficientes de correlação dos componentes periféricos com o PCV foram positivos, aparas $(\mathrm{r}=0,77 ; \mathrm{P}>0,0001)$; cabeça $(\mathrm{r}=0,84 ; \mathrm{P}>0,0001)$; couro $(\mathrm{r}=0,72 ; \mathrm{P}>0,0001)$ e o somatório destes $(\mathrm{r}=0,83 ; \mathrm{P}>0,0001)$. Estes resultados corroboram a afirmação anterior acerca da similaridade entre tratamentos para estas características.

Neste estudo os pesos de orelhas, patas e vassoura da cauda foram somados e considerados como aparas, uma vez que são variáveis de menor relevância em relação a outros órgãos que compõem o corpo vazio. Na linha de abate a retirada destes órgãos é feita entre a sangria e a esfola, e são influenciados principalmente por idade, peso de abate e composição genética dos bovinos ${ }^{(7,9)}$.

O peso de cabeça médio dos novilhos foi de $12,57 \mathrm{~kg}$ e correspondeu a 4,11\% do peso de corpo vazio. A similaridade para esta característica deve-se à idade dos animais em que as castrações foram realizadas, todas em fase pré-púbere. Estudos avaliando o desenvolvimento corporal de bovinos machos castrados cirurgicamente ou imunologicamente em idade pré-púbere verificaram que os animais de ambos os grupos apresentaram desenvolvimento similar ${ }^{(10,11)}$; dessa forma, a mesma intensidade de crescimento induz a semelhanças nos componentes periféricos. A castração em idade pré-púbere, sem que haja aproveitamento marcante da testosterona como hormônio natural de crescimento, é prática comumente realizada, na região Sul do Brasil.

Caso tivesse havido um grupo castrado mais tardiamente poderia ocorrer o pronunciamento marcante do dimorfismo sexual, com diferenças no peso de cabeça, como nos estudos de Kuss et al. ${ }^{(1)}$ que obtiveram maior peso deste componente para novilhos não castrados em relação à castrados. Com o avanço do dimorfismo sexual, espera-se uma alteração do calibre e tamanho das estruturas ósseas dos bovinos, elevando principalmente o peso de cabeça e patas ${ }^{(12)}$. Na região da cabeça dos bovinos encontram-se partes comercializáveis que auxiliam na geração de receita no frigorífico, como a carne de cabeça, principalmente o músculo masseter, o cérebro e a língua, sendo esta última um produto que apresenta boa aceitação pelo mercado consumidor.

O peso de couro médio obtido neste estudo foi de $29,54 \mathrm{~kg}$ e representou $9,62 \%$ do PCV. O peso deste componente é alterado principalmente pelo peso de abate, idade de abate e grupo genético ${ }^{(8)}$, no entanto, como no presente trabalho estes fatores foram similares, justifica-se a inobservância de diferença significativa para o componente couro. Dentre os componentes periféricos, o couro destacase como aquele que apresenta maior valor econômico agregado, principalmente para a indústria frigorífica e desempenha importante papel em outros setores da economia, como a indústria de calçados e vestuário ${ }^{(9)}$. No estudo de Vaz et al. ${ }^{(2)}$, ao se analisar as receitas obtidas pela indústria frigorífica com os componentes não carcaça, verificou-se que o couro é o item que gera a maior receita industrial e, juntamente com o fígado, são responsáveis por $58 \%$ do valor gerado pelos componentes não carcaça.

A ausência de diferenças estatísticas nas variáveis descritas nas Tabelas 1 e $2(\mathrm{P}>0,05)$ são benéficas no sentido de validar a tecnologia da imunocastração, demonstrando que a mesma é igualmente eficiente à castração cirúrgica. Logo, sob este prisma a imunocastração é mais uma alternativa de manejo que pode ser adotada pelos produtores, reduzindo todos os inconvenientes da castração cirúrgica e melhorando os aspectos de bem-estar animal. A castração cirúrgica, juntamente com a descorna, são os procedimentos mais traumáticos pelos quais os bovinos criados em ambiente pastoril são submetidos ao longo da vida produtiva ${ }^{(13)}$. 
Não houve influência dos tipos de castração sobre o desenvolvimento dos órgãos vitais (coração, rins, pulmões e fígado) e do baço, tanto em peso absoluto como relativo a $100 \mathrm{~kg}$ de PCV (Tabela 3).

Tabela 3. Médias, coeficiente de variação e probabilidade dos órgãos internos e sangue expressos em peso absoluto $(\mathrm{kg})$ e por $100 \mathrm{~kg}$ de corpo vazio $(\mathrm{PCV})$ de novilhos submetidos à castração cirúrgica ou imunológica

\begin{tabular}{|c|c|c|c|c|c|c|}
\hline \multirow{3}{*}{ Variáveis } & \multicolumn{4}{|c|}{ Castração } & \multirow{3}{*}{$\begin{array}{l}\text { CV } \\
(\%)\end{array}$} & \multirow{3}{*}{$P$ valor } \\
\hline & \multicolumn{2}{|c|}{ Cirúrgica } & \multicolumn{2}{|c|}{ Imunológica } & & \\
\hline & Nascer & Desmame & 3 doses & 4 doses & & \\
\hline Coração, kg & 1,07 & 0,99 & 1,02 & 1,05 & 12,10 & 0,4023 \\
\hline Coração, \% PCV & 0,34 & 0,34 & 0,33 & 0,34 & 8,54 & 0,6633 \\
\hline Rins, kg & 0,70 & 0,63 & 0,64 & 0,70 & 13,96 & 0,0906 \\
\hline Rins, \% PCV & 0,22 & 0,21 & 0,20 & 0,22 & 10,29 & 0,0851 \\
\hline Pulmões, kg & 4,22 & 3,92 & 4,08 & 4,15 & 10,78 & 0,4142 \\
\hline Pulmões, \% PCV & 1,34 & 1,34 & 1,31 & 1,33 & 6,75 & 0,8792 \\
\hline Fígado, $\mathrm{kg}$ & 3,91 & 3,56 & 3,73 & 3,98 & 13,76 & 0,1792 \\
\hline Figado, \% PCV & 1,24 & 1,22 & 1,19 & 1,28 & 7,15 & 0,1324 \\
\hline Baço, kg & 1,18 & 1,07 & 1,06 & 1,29 & 20,64 & 0,2181 \\
\hline Baço, \% PCV & 0,37 & 0,37 & 0,34 & 0,42 & 18,66 & 0,2893 \\
\hline Total de internos, $\mathrm{kg}$ & 11,10 & 10,19 & 10,55 & 11,19 & 11,09 & 0,1163 \\
\hline Total internos, \% PCV & $3,53^{\mathrm{ab}}$ & $3,49^{\mathrm{ab}}$ & $3,39^{b}$ & $3,61^{\mathrm{a}}$ & 5,29 & 0,0472 \\
\hline Sangue, $\mathrm{kg}$ & 13,83 & 13,44 & 13,60 & 14,31 & 11,10 & 0,5346 \\
\hline Sangue, \% PCV & 4,41 & 4,59 & 4,38 & 4,62 & 6,04 & 0,0783 \\
\hline
\end{tabular}

Médias seguidas na linha com letras diferentes diferem entre si pelo teste de Tukey $(\mathrm{P}<0,05)$.

P valor - probabilidade; CV (\%) - Coeficiente de variação.

Os órgãos internos, também chamados de vísceras vermelhas, correlacionam-se positivamente com o PCV que neste estudo também foi similar entre tratamentos. O PCV apresentou correlação com coração ( $\mathrm{r}=0,71 ; \mathrm{P}<0,0001)$, pulmões $(\mathrm{r}=0,79 ; \mathrm{P}<0,0001)$, rins ( $\mathrm{r}=0,69 ; \mathrm{P}<0,0001)$ e fígado $(0,84$; $\mathrm{P}<0,0001)$. Todavia, o componente baço não se correlacionou com o PCV. A similaridade no PCV entre os tratamentos e sua associação com estes órgãos justificam a resposta obtida, somando-se ao fato de que a dieta dos animais era exatamente a mesma, portanto, com o mesmo nível energético que pode ser outro fator a interferir no desenvolvimento das vísceras vermelhas. É esperado que bovinos alimentados com altas densidades energéticas possuam maior desenvolvimento destes órgãos, para atender a um metabolismo mais intenso ${ }^{(14)}$. Dentre os órgãos vitais, o fígado é o de maior relevância por ser aquele que participa mais ativamente do metabolismo de nutrientes, desencadeado pelo cosumo de alimentos, exigências energéticas e taxa metabólica ${ }^{(15)}$, além de ser importante fonte de agregação de valor na indústria frigorífica ${ }^{(2)}$.

Os resultados obtidos para peso de fígado estão em acordo com Miguel ${ }^{(16)}$ que avaliou o peso deste órgão em bovinos machos e verificou similaridade entre castrados cirurgicamente e imunocastrados, com vacina de mesmo princípio ativo e estes com peso de fígado inferior a um grupo não castrado. 
Com relação ao somatório dos órgãos internos, verificamos valores similares em peso absoluto, com valor médio de $10,76 \mathrm{~kg}$ (Tabela 3). Todavia, quando estes foram expressos por $100 \mathrm{~kg}$ PCV obtevese diferença significativa entre os dois protocolos de castração imunológica $(\mathrm{P}<0,05)$. Novilhos que receberam quatro aplicações da vacina apresentaram maior conjunto destes órgãos que aqueles que receberam três aplicações $(3,61$ vs. $3,39 \mathrm{~kg}$ por $100 \mathrm{~kg}$ PCV), enquanto os submetidos à castração cirúrgica foram similares aos demais, independentemente da idade de realização do procedimento. Estes resultados são contraditórios, porque a expectativa era de que se algum tratamento fosse beneficiado pela metodologia de castração seria o de três aplicações, em função do maior período, em que poderia haver ação de testosterona, como relatado anteriormente.

Diante do exposto acima, a hipótese mais provável para tal diferença é que as pequenas variações entre os dois tratamentos com imunocastração em cada um dos órgãos internos, quando somados e ajustados ao peso corporal vazio, que foi muito próximo $(310,40 v s .309,9 \mathrm{~kg}$, respectivamente para três e quatro doses), refletiu em diferença estatística. Entretanto, cabe ressaltar ainda que mais estudos com foco em estratégias de utilização da imunocastração e seu reflexo sobre os órgãos vitais dos bovinos são necessários.

Estudos que avaliaram o conjunto de órgãos internos, ajustados para PCV em novilhos castrados e não castrados, não observaram influência da condição sexual sobre a participação dos órgãos, uma vez que o desenvolvimento dos mesmos acompanhou o desenvolvimento corporal dos animais ${ }^{(1,17)}$. $\mathrm{O}$ volume de sangue não foi alterado em função dos métodos e idades de castração, nas duas formas em que foi expresso. Este comportamento está em sincronia com o peso dos órgãos internos, pois de acordo com Pacheco et al. ${ }^{(9)}$ o aumento do volume de sangue está associado ao aumento dos órgãos vitais e trato gastrintestinal, necessitando maior aporte sanguíneo para manter a taxa metabólica de animais com maior massa de órgãos. A correlação entre o sangue e o somatório de órgãos internos foi de $0,75(\mathrm{P}<0,0001)$. Associação entre estas duas variáveis já foi relatada por Kuss et al. ${ }^{(1)} \mathrm{e}$ Cattelam et al. ${ }^{(17)}$ que encontraram, respectivamente, valores de correlação de 0,66 e 0,61.

O desenvolvimento dos componentes do trato gastrintestinal está apresentado na Tabela 4, onde podemos observar que as idades e métodos de castração avaliados não exerceram influência sobre estes órgãos, tanto em peso absoluto quanto ajustado para $100 \mathrm{~kg}$ de $\mathrm{PCV}(\mathrm{P}>0,05)$.

A similaridade observada para estas características está associada à equivalência do PCV entre os tratamentos e também a idade em que todos os animais foram castrados, que não permitiu efeito marcante de hormônios androgênicos sobre o desenvolvimento dos componentes gástricos. A correlação encontrada entre o somatório dos componentes do trato digestivo com o PCV foi de 0,62 ( $\mathrm{P}<0,0001)$, demonstrando que a elevação de um leva a aumento também do outro para animais, em mesmas condições fisiológicas. Neste estudo, embora a castração tenha ocorrido em diferentes épocas e com diferentes métodos, na ocasião do abate todos os novilhos apresentavam mesma condição sexual, portanto, semelhantes fisiologicamente.

Em novilhos de diferentes condições sexuais Kuss et al. ${ }^{(1)}$ observaram que animais não castrados apresentaram maior peso de trato gastrintestinal total que novilhos castrados, porém quando foi ajustado ao PCV esta diferença deixou de existir. Cattelam et al. ${ }^{(1)}$ obtiveram maior peso de intestinos, em valor absoluto e ajustado para $100 \mathrm{~kg}$ de corpo vazio, para novilhos não castrados em relação a castrados. Os resultados destes autores sugerem que novilhos castrados possuem taxa metabólica menor que não castrados, com menor demanda nutricional, acompanhando o ímpeto de crescimento animal $^{(17)}$. Portanto, com base no exposto podemos inferir que assim como em outros 
componentes não carcaça descritos anteriormente na avaliação do trato gastrintestinal a castração imunológica também foi eficiente, comportando-se da mesma maneira que a castração cirúrgica.

Tabela 4. Médias, coeficiente de variação e probabilidade dos componentes do trato digestório expressos em peso absoluto $(\mathrm{kg})$ e por $100 \mathrm{~kg}$ de corpo vazio (PCV) de novilhos submetidos à castração cirúrgica ou imunológica

\begin{tabular}{lccccccc}
\hline \multirow{2}{*}{ Variáveis } & \multicolumn{5}{c}{ Castração } & & \\
\cline { 2 - 5 } & \multicolumn{2}{c}{ Cirúrgica } & Imunológica & CV (\%) & P valor \\
\cline { 2 - 5 } & Nascer & Desmame & 3 doses & 4 doses & & \\
\hline Rúmen-retículo, kg & 5,45 & 5,35 & 5,64 & 5,65 & 14,59 & 0,7694 \\
Rúmen-retículo, \% PCV & 1,74 & 1,83 & 1,81 & 1,82 & 11,96 & 0,7012 \\
Omaso, kg & 6,45 & 5,83 & 5,97 & 6,00 & 17,23 & 0,5446 \\
Omaso, \% PCV & 2,07 & 2,00 & 1,93 & 1,94 & 17,07 & 0,7599 \\
Abomaso, kg & 1,12 & 1,03 & 1,10 & 1,08 & 23,91 & 0,8370 \\
Abomaso, \% PCV & 0,36 & 0,35 & 0,35 & 0,35 & 22,79 & 0,9924 \\
Intestinos, kg & 8,10 & 7,32 & 7,95 & 8,06 & 12,40 & 0,1899 \\
Intestinos, \% PCV & 2,56 & 2,51 & 2,55 & 2,61 & 10,43 & 0,8141 \\
Trato gastrintestinal, kg & 21,14 & 19,55 & 20,67 & 20,80 & 11,36 & 0,3808 \\
Trato gastrintestinal, \% PCV & 6,76 & 6,70 & 6,65 & 6,73 & 9,56 & 0,9821 \\
\hline
\end{tabular}

P valor - probabilidade; CV (\%) - Coeficiente de variação.

A similaridade no peso do trato gastrintestinal é uma resposta bastante interessante, uma vez que este conjunto de órgãos interfere consideravelmente em outras características como o rendimento de carcaça, que são de interesse tanto para produtor quanto para indústria frigorífica. Neste trabalho os rendimentos de carcaça quente e fria e os componentes do trato gastrintestinal relacionaram-se negativamente, quando ambos foram ajustados para PCV. A exceção foi o peso de omaso, que não se correlacionou significativamente com os rendimentos de carcaça ajustados a PCV. O rendimento de carcaça fria em percentual do PCV apresentou os seguintes valores de correlação com os componentes do trato digestivo ajustado ao $\mathrm{PCV}$ : rúmen-retículo $(\mathrm{r}=-0,38 ; \mathrm{P}=0,0134)$, abomaso $(\mathrm{r}=-0,41 ; \mathrm{P}=0,0031)$, intestinos $(\mathrm{r}=-0,39 ; \mathrm{P}=0,0069)$ e trato gastrintestinal total $(\mathrm{r}=-0,46 ; \mathrm{P}=0,0010)$.

Diferentemente dos outros componentes não carcaça, as gorduras cavitárias, nas duas formas em que foram expressas, sofreram influência das estratégias de castração (Tabela 5).

Neste estudo o intervalo entre castrações para os tratamentos, cirúrgica ao nascimento e imunológica com quatro aplicações, foi de 224 dias, ao passo que com três aplicações foi de 284 dias. Esta diferença de 60 dias nos permite considerar que foi este o principal motivo para evidenciar diferenças na deposição de tecido adiposo visceral. Embora não tenha havido mudanças no desenvolvimento corporal dos animais, ao longo do período experimental, evidenciado pela similaridade do peso corporal vazio (Tabela 1), considerando que foram abatidos juntos (mesma idade), a composição deste ganho de peso variou entre os dois grupos com maior intervalo entre castrações, em que houve menor deposição de gordura visceral nos imunocastrados com três doses, em relação aos castrados ao nascimento $(\mathrm{P}<0,05)$. 
Tabela 5. Médias, coeficiente de variação e probabilidade para as gorduras cardíaca, pélvica e renal (GCPR); gordura de toalete e gordura do trato gastrintestinal (GTGI) expressas em peso absoluto $(\mathrm{kg})$ e por $100 \mathrm{~kg}$ de corpo vazio $(\mathrm{PCV})$ de novilhos submetidos à castração cirúrgica ou imunológica

\begin{tabular}{lccccccc}
\hline & \multicolumn{5}{c}{ Castração } & \multirow{2}{*}{ CV } & \multirow{2}{*}{ Variáveis } \\
\cline { 2 - 4 } & \multicolumn{2}{c}{ Cirúrgica } & \multicolumn{2}{c}{ Imunológica } & & P valor \\
\cline { 2 - 5 } & Nascer & Desmame & 3 doses & 4 doses & \\
\hline GCPR, kg & $3,48^{\mathrm{a}}$ & $2,82^{\mathrm{ab}}$ & $2,43^{\mathrm{b}}$ & $2,90^{\mathrm{ab}}$ & 10,96 & 0,0068 \\
GCPR, \% PCV & $1,09^{\mathrm{a}}$ & $0,97^{\mathrm{ab}}$ & $0,78^{\mathrm{b}}$ & $0,94^{\mathrm{ab}}$ & 8,74 & 0,0076 \\
Gordura de Toalete, kg & 0,87 & 0,84 & 0,68 & 0,86 & 22,48 & 0,1851 \\
Gordura de Toalete, \% PCV & 0,28 & 0,29 & 0,22 & 0,28 & 20,49 & 0,0789 \\
GTGI, kg & $7,51^{\mathrm{a}}$ & $6,52^{\mathrm{ab}}$ & $5,98^{\mathrm{b}}$ & $6,65^{\mathrm{ab}}$ & 13,79 & 0,0099 \\
GTGI, \% PCV & $2,38^{\mathrm{a}}$ & $2,24^{\mathrm{ab}}$ & $1,92^{\mathrm{b}}$ & $2,16^{\mathrm{ab}}$ & 12,21 & 0,0455 \\
Total de gorduras, kg & $11,86^{\mathrm{a}}$ & $10,19^{\mathrm{ab}}$ & $9,10^{\mathrm{b}}$ & $10,41^{\mathrm{ab}}$ & 12,36 & 0,0351 \\
Total de gorduras, \% PCV & $3,75^{\mathrm{a}}$ & $3,50^{\mathrm{ab}}$ & $2,92^{\mathrm{b}}$ & $3,37^{\mathrm{ab}}$ & 11,21 & 0,0348 \\
\hline
\end{tabular}

Médias seguidas na linha com letras diferentes diferem entre si pelo teste de Tukey $(\mathrm{P}<0,05)$.

P valor - probabilidade; CV (\%) - Coeficiente de variação.

Embora sejam encontradas poucas informações na literatura sobre a composição corporal de bovinos machos castrados ao nascimento, os resultados obtidos nos permitem inferir que este manejo interfere no metabolismo animal incrementando a deposição de tecido adiposo visceral. Prado et al. ${ }^{(18)}$ verificaram incremento significativo na gordura de acabamento de novilhos castrados, em relação a não castrados, atribuindo este resultado ao maior metabolismo glicolítico em detrimento do hipertrófico em animais castrados. Embora no presente estudo todos os animais sejam castrados, o intervalo entre castrações acabou alterando a deposição de gordura visceral. Mesmo sendo gorduras localizadas em diferentes regiões do corpo dos animais, a explicação utilizada por Prado et al. ${ }^{(18)}$ acaba sendo corroborada por nossos resultados. Isto porque, segundo Di Marco et al. ${ }^{(19)}$, a condição sexual é um dos fatores que mais afetam a deposição de gordura em bovinos, e animais castrados iniciam esta deposição mais precocemente. Além disso, os sítios de deposição de gordura seguem como rota prioritária as regiões visceral, intermuscular, subcutânea e intramuscular ${ }^{(19)}$. Logo, no presente estudo o intervalo de 284 dias entre as castrações acabou desencadeando diferenças significativas na participação da primeira gordura a ser depositada.

Costa et al. ${ }^{(20)}$ observaram que a condição sexual de bovinos não alterou a participação da maioria dos órgãos internos e do trato digestivo, mas as gorduras do trato gastrintestinal foram superiores em bovinos castrados em relação ao não castrados. No presente estudo, embora todos os animais tenham sido castrados, se considerarmos o intervalo entre castrações já descrito anteriormente, os resultados seguem uma lógica em comum com o trabalho mencionado acima. Por outro lado, ao comparar a castração imunológica à cirúrgica outras pesquisas obtiveram percentagem estimada de gordura cardíaca, pélvica e renal semelhante, porém para novilhos terminados em confinamento ${ }^{(10,21)}$. O conjunto destas gorduras representa o KPH, utilizado nos Estados Unidos pelo sistema USDA para determinação do Yeld Grade (grau de rendimento) de carcaças bovinas. 
Reid et al. ${ }^{(22)}$ citam a gordura como o principal constituinte do corpo vazio que causa variações na composição corporal, uma vez que flutuações observadas nos demais constituintes corporais ocorrem como reflexo das mudanças na quantidade de gordura presente no corpo. Maiores acúmulos de gorduras cavitárias são tidos como fator negativo, pois animais com maior deposição destas gorduras possuem maior exigência nutricional de mantença ${ }^{(23)}$, além disso, para o frigorífico estas gorduras também não são interessantes por apresentaram pouca representatividade na remuneração ao frigorífico, dentre os componentes não carcaça ${ }^{(2)}$. Todavia, devemos considerar que esta é a primeira gordura a ser depositada no corpo do animal e embora não seja interessante pelos fatores mencionados acima, faz-se necessária para que se tenham depósitos de gordura de acabamento e até de marmoreio que atendam aos anseios da indústria e do próprio consumidor.

Independentemente do protocolo de imunocastração utilizado, no momento do abate os animais não diferiram quanto ao peso, comprimento e diâmetro dos testículos (Tabela 6). Esta resposta indica que ambos os protocolos apresentaram a mesma eficácia sobre a inibição da função reprodutiva dos novilhos, percebida pela similaridade nessas variáveis.

Tabela 6. Médias, coeficiente de variação e probabilidade para circunferência testicular, comprimento testicular, peso conjugado dos testículos em peso absoluto (g) e por $100 \mathrm{~kg}$ de corpo vazio $(\mathrm{PCV})$ de novilhos submetidos à castração cirúrgica ou imunológica

\begin{tabular}{lcccc}
\hline \multirow{2}{*}{ Variáveis } & \multicolumn{2}{c}{ Castração imunológica } & \multirow{2}{*}{ CV (\%) } & \multirow{2}{*}{ P valor } \\
\cline { 2 - 3 } & 3 doses & 4 doses & & \\
\hline Perímetro testicular (cm) & 12,79 & 12,33 & 29,10 & 0,7510 \\
Comprimento testicular (cm) & 10,89 & 10,79 & 30,77 & 0,9451 \\
Peso conjugado dos testículos (g) & 330,08 & 323,00 & 30,22 & 0,8791 \\
Peso dos testículos, \% PCV & 0,10 & 0,10 & 28,13 & 0,8433 \\
\hline
\end{tabular}

$\mathrm{P}$ valor - probabilidade; CV (\%) - Coeficiente de variação.

Esta semelhança já era esperada, uma vez que na ocasião do abate os novilhos dos dois grupos já se caracterizavam como castrados imunologicamente, o que suprime a produção hormonal de FSH, LH e testosterona. Esta supressão hormonal impede que o desenvolvimento testicular de bovinos imunocastrados seja semelhante a não castrados, com marcante redução de perímetro e peso dos testículos ${ }^{(11)}$. Ao analisarmos do ponto de vista prático e econômico, este resultado é bastante relevante, pois estes indicadores juntamente com as demais variáveis discutidas neste trabalho nos permitem recomendar o protocolo com três aplicações da vacina Bopriva ${ }^{\circledR}$ para novilhos imunocastrados desde idade pré-púbere. Isto porque implica em redução de manejo e principalmente de custos.

As variáveis que foram discutidas no trabalho envolvendo a estatística de correlação de Pearson estão apresentados na Tabela 7, com seus respectivos valores de correlação e probabilidade. 


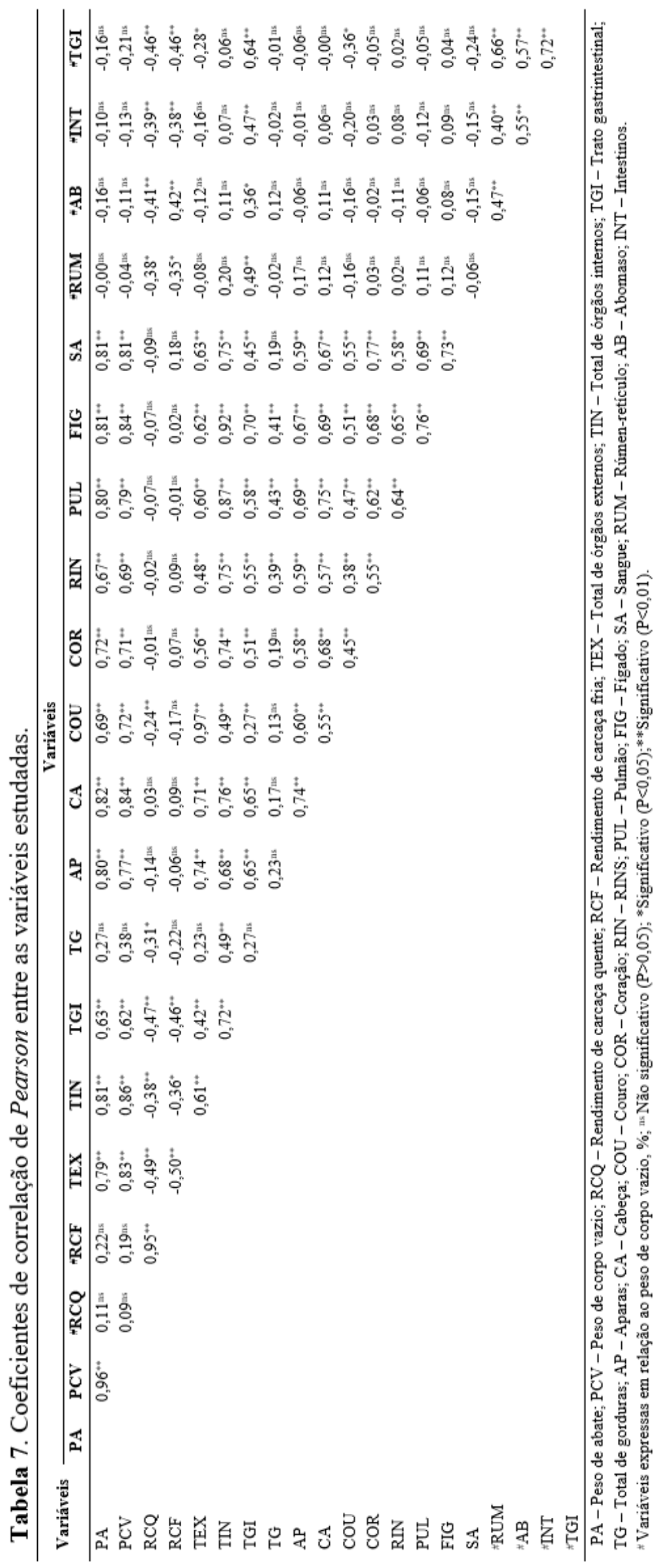




\section{Conclusões}

Embora não altere os demais componentes não carcaça, a castração imunológica com três doses da vacina Bopriva $^{\circledR}$, em que a aplicação definitiva ocorre aos nove meses de idade, reduz a deposição de gordura visceral em relação à castração cirúrgica ao nascimento, em novilhos Aberdeen Angus abatidos aos 19 meses.

\section{Agradecimentos}

À Zoetis pela parceria estabelecida, possibilitando a implantação dos protocolos de imunocastração, além de responsabilizar-se pelo controle sanitário e aquisição do alimento concentrado utilizado na terminação dos novilhos.

Ao proprietário dos animais e fazenda pela possibilidade da realização do estudo, e também à CAPES pela concessão da bolsa de mestrado ao primeiro autor.

\section{Referências}

1. Kuss F, Barcellos JOJ, López J, Restle J, Moletta JL, de Paula MC. Componentes não-integrantes da carcaça de novilhos não-castrados ou castrados terminados em confinamento e abatidos aos 16 ou 26 meses de idade. Revista Brasileira de Zootecnia [Internet]. 2008 [Acesso Nov 2016];37(10):1829-1836. Disponível em: <http://dx.doi.org/10.1590/S1516-35982008001000017>. Portuguese.

2. Vaz FN, Restle J, Pádua JT, Fonseca CA, Pascoal LL, Severo MM. Componentes não carcaça de bovinos Nelore abatidos com diferentes pesos. Ciência Animal Brasileira [Internet]. 2015 [Acesso Maio 2017];16(3):313-323. Disponível em: 〈http://dx.doi.org/10.1590/1089-6891v16i318694〉. Portuguese.

3. Hocquette JF, Richardson RI, Prache S, Medale F, Duffy G, Scollan ND. The future trends for research on quality and safety of animal products. Italian Journal of Animal Science [Internet]. 2005 [Acesso Jan 2017]; 4(3):49-72. Disponível em: 〈http://dx.doi.org/10.4081/ijas.2005.3s.49>. English.

4. Miguel GZ, Faria MH, Roça RO, Santos CT, Suman SP, Faitarone ABG, et al. Immunocastration improves carcass traits and beef color attributes in Nellore and Nellore x Aberdeen Angus crossbred animals finished in feedlot. Meat Science [Internet]. 2014 [Acesso Nov 2016];96(2 Pt A):884-891. Disponível em: <http://doi.org/10.1016/j.meatsci.2013.08.030>. English.

5. Freitas VM, Leão KM, Araújo Neto FR, Marques TC, Ferreira RM, Garcia LLF, et al. Effects of surgical castration, immunocastration and homeopathy on the performance, carcass characteristics and behaviour of feedlot-finished crossbred bulls. Semina: Ciências Agrárias [Internet]. 2015 [Acesso Jan 2017];36(3):17251734. Disponível em: 〈http://dx.doi.org/10.5433/1679-0359.2015v36n3p1725>. English.

6. Brasil. Resolução no .928 , de 13 de Novembro de 2009. Altera dispositivos da CFMV nº 877/2008, publicada no DOU de 19-03-2008, seção 1, págs. 173 e 174, e dá outras providências. Diário Oficial da União, Brasília, DF, n.243, p.192, 2009. Seção I [acesso Abr 2015]. Disponível em: <http://www.cfmv.org.br/consulta/arquivos/877.pdf>. Portuguese.

7. Cattelam J, Freitas LS, Brondani IL, Silva JHS, Arboitte MZ, Weise MS. Características dos componentes externos e das gorduras descartadas de novilhos superprecoces não-castrados ou castrados de dois genótipos terminados em confinamento. Revista Brasileira de Zootecnia [Internet]. 2011 [Acesso Nov 2016];40(8):17741780. Disponível em: <http://dx.doi.org/10.1590/S1516-35982011000800022〉. Portuguese. 
8. Menezes LFG, Brondani IL, Restle J, Alves Filho DC, Callegaro AM, Weise MS. Características dos componentes não integrantes da carcaça de novilhos superjovens da raça Devon, terminados em diferentes sistemas de alimentação. Arquivo Brasileiro de Medicina Veterinária e Zootecnia [Internet]. 2011[Acesso Fev 2017];63(3):372-381. Disponível em: 〈http://dx.doi.org/10.1590/S0102-09352011000200015〉. Portuguese.

9. Pacheco PS, Restle J, Silva JHS, Arboitte MZ, Alves Filho DC, Freitas AK, et al. Características das partes do corpo não-integrantes da carcaça de novilhos jovens e superjovens de diferentes grupos genéticos. Revista Brasileira de Zootecnia [Internet]. 2005 [Acesso Dez 2016];34(5):1678-1690. Disponível em: <http://www.scielo.br/pdf/rbz/v34n5/26650.pdf>. Portuguese.

10. Aïssat D, Sosa JM, Avila DM, Bertrand KP, Reeves JJ. Endocrine, growth, and carcass characteristics of bulls immunized against luteinizing hormone-releasing hormone fusion proteins. Journal of Animal Science [Internet]. 2002[Acesso Out 2016];80(9):2209-2213. Disponível em: <http://dx.doi.org/10.2527/2002.8092209x $>$. English.

11. Janett F, Gerig T, Tschuor AC, Amataiakul-Chantler S, Walker J, Howard R, et al. Effect of vaccination against gonadotropin-releasing factor (GnRF) with Bopriva ${ }^{\circledR}$ in the prepubertal bull calf. Animal Reproduction Science [Internet]. 2012[Acesso Jan 17];131(1-2):72-80. Disponível em: <http://dx.doi.org/10.1016/j.anireprosci.2012.02.012>. English.

12. Berg RT, Butterfield RM. New concepts of cattle growth. Sydney: Sydney University Press; 1976. 240 p. English.

13. Grandin T. Animal welfare and society concerns finding the missing link. Meat Science [Internet]. 2014 [Acesso Dez 2016];98(3):461-469. Disponível em: <http://doi.org/10.1016/j.meatsci.2014.05.011>. English.

14. Almeida Júnior GA, Costa C, Carvalho SMR, Panichi A, Persichetti Júnior P. Características de carcaças e dos componentes não-carcaça de bezerros holandeses alimentados após o desaleitamento com silagem de grãos úmidos ou grãos secos de milho ou sorgo. Revista Brasileira de Zootecnia [Internet]. 2008 [Acesso Mar 2017];37(1):157-63. Disponível em: 〈http://dx.doi.org/10.1590/S1516-35982008000100023〉. Portuguese.

15. Owens FN, Dubeski P, Hanson CF. Factors that alter the growth and development of ruminants. Journal of Animal Science [Internet]. 1993 [Acesso Maio 2017];71:3138-3150. Disponível em: <https://www.researchgate.net/profile/Fred Owens/publication/14927831 Factors that alter growth and d evelopment_of_ruminants/links/54ec9a280cf2465f532fbb63.pdf >. English.

16. Miguel GZ. Imunocastração no desempenho, características de carcaça e qualidade da carne de bovinos terminados em confinamento [Tese]. Botucatu: Universidade Estadual Paulista, Faculdade de Medicina Veterinária e Zootecnia; 2013. 155 f. [Acesso Nov 2016]. Disponível em: <https://repositorio.unesp.br/bitstream/handle/11449/106308/miguel gz dr botfmvz.pdf?sequence=1>. Portuguese.

17. Cattelam J, Silveira MF, Sachet RH, Freitas LS, Pacheco RF, Moura RM, et al Órgãos internos e trato digestório de novilhos superprecoces não castrados ou castrados, de dois grupos genéticos. Arquivo Brasileiro de Medicina Veterinária e Zootecnia [Internet]. 2011 [Acesso Dez 2016];63(5):1167-1174. Disponível em: <http://dx.doi.org/10.1590/S0102-09352011000500018>. Portuguese.

18. Prado CS, Pádua JT, Corrêa MPC, Ferraz JBS, Miyagi ES, Rezende LS. Comparação de diferentes métodos de avaliação da área de olho de lombo e cobertura de gordura em bovinos de corte. Ciência Animal Brasileira [Internet]. 2004 [Acesso Jul 2017];5(3):141-148. Disponível em: $<$ https://www.revistas.ufg.br/vet/article/view/26837/15357>. Portuguese.

19. Di Marco ON, Barcellos JOJ, Costa EC. Crescimento de bovinos de corte. Porto Alegre: Universidade Federal do Rio Grande do Sul, 2007. 276 p. Portuguese.

20. Costa DPB, Rodrigues VC, Hiratsuka, KP, Mourão RC, Lima ES, Costa QPB, et al. Peso das vísceras de búfalos e bovinos castrados e inteiros. Agropecuária Científica no Semi-Árido [Internet]. 2010 [Acesso Jul 
2017];6(1):33-39. Disponível em: 〈http://revistas.ufcg.edu.br/acsa/index.php/ACSA/article/view/60/pdf>. Portuguese.

21. Huxssol CC, Price EO, Adams TE. Testis function, carcass traits, and aggressive behavior of beef bulls actively immunized against gonadotropin-releasing hormone. Journal of Animal Science [Internet]. 1998 [Acesso Out 2016];76(7):1760-1766. Disponível em: 〈http://dx.doi.org/10.2527/1998.7671760x >. English.

22. Reid JT, Bensadoun LS, Bull JH, Burton JH, Gleeson PA, Han IK, et al. Some peculiarities in the body composition of animals: interspecific, sex, age and the influence of nutrition. In: Body composition in animals and man. $1^{\text {st }}$ ed. Washington: National Academy Press, 1972. p. 19-44. English.

23. Owens FN, Gill DR, Secrist DS, Coleman SW. Review of some aspects of growth and development of feedlot cattle. Journal of Animal Science [Internet]. 1995 [Acesso Jan 2017];73(10):3152-3172. Disponível em: 〈http://dx.doi.org/10.2527/1995.73103152x >. English. 